\title{
Chapter 8 \\ Comparison of Imaginaries Across Countries and Wider Implications
}

\begin{abstract}
In Part II of the book we asked why RRI develops differently in different national contexts. We argued that this is because RRI can be regarded as a model of the relation between science and society. As all studied countries have established STI systems, all of them have different imaginaries that cover this relationship, though these are not always fully explicit. National imaginaries have different features for different reasons. They cannot simply be ordered on a linear scale of 'progression' towards RRI (Mejlgaard et al. 2018). RRI promotors have to engage with these imaginaries in order to properly align RRI with them. We have illustrated our claim by studying twelve countries' sociotechnical imaginaries on STI in Chap. 7, using RRIPractice's national reports as data. In this chapter we compare and abstract from the national sociotechnical imaginaries on STI. While some policy goals and participation models are common across many countries, there are also salient differences with regards to policy goals, framings of the responsibilities of scientists, administrative styles and public participation goals and mechanisms. We sketch salient differences and how they matter for the implementation of the 'RRI model'.
\end{abstract}

Keywords Sociotechnical imaginaries $\cdot$ Responsible research and innovation $\cdot$ STI policy goals $\cdot$ STI framing $\cdot$ Administrative style $\cdot$ Public participation

\subsection{STI Policy Goals}

When looking at STI policy goals, there is a salient difference between policy goals aimed at economic growth and international competitiveness, and non-economic societal goals, such as sustainable development. Though both kinds of goals are intended to ultimately benefit society, they can be in tension, as shown in the reports of Australia (Sehic and Ashworth 2018), China (Zhao et al. 2018), Italy (Neresini and Arnaldi 2018), the Netherlands (van der Molen et al. 2018), the UK (Pansera and Owen 2018) and the US (Doezema and Guston 2018). All these reports identify concerns that an overly dominant focus on economic goals could be at the expense of societal values or, in academia, critical thinking and curiosity-driven research. The US is the most competitive economy in the world (World Economic Forum 2018) 
and also the one that spends the most on research in absolute terms (US report, p. 8). Yet its reliance on market governance mechanisms in technology assessment leaves little room for discussion on which societal values innovation should advance. At the same time, the political power of some economic actors has distorted both market governance and the democratic process (ibid., p. 44).

With regards to the fit of policy goals to those in the RRI imaginary, in principle both economic and societal goals can fit with the RRI imaginary, as economic goals tend to be ultimately adopted for their societal value (e.g. for creating jobs, or goods or services to meet societal needs as expressed on the market). However, several national reports note that a lack of reflexivity on economic goals can lead to other societal values being (implicitly) marginalised. For example, the Netherlands report mentions critical discussions among academics on the risk of commodification and 'economic salvation' of research (pp. 19, 28). The UK report has identified the singleminded political focus on productivity and economic growth as a great challenge to RRI more generally (p. 29). And the US report shows the shortcomings of the US's market governance system of STI, highlighting how market governance mechanisms do little to facilitate discussions about desirable futures (p. 43). A counterexample to this trend is the Italy report, that shows that good examples of reflexive governance can come from the private sector, such as responsible innovation certification (pp. 2324). However, no report signals a reverse situation, where a focus on societal goals threatens to eclipse economic development. This suggests that economic goals tend to have an unquestioned primacy in policy-making that, especially in a 'systems of innovation' model, and can easily eclipse societal goals, while at the same time being resistant to public scrutiny and reflection. For further research, it would be interesting to explore what RRI could mean for research in economics as a scientific discipline, as well as for economic policy-making.

\subsection{STI Framing}

Most of the national case study reports present several framings of the goals of STI policy and the responsibilities of scientists. A prominent frame is the pursuit of scientific excellence, as evaluated by metrics such citation count or journal impact factor. Societal value/valorisation of research/contribution to socio-economic development is also prominent, though both its focus and its mode of operationalisation differs per country. In some countries, the focus lies more on economic value, for example, in the Netherlands, the UK and the US. In other countries the focus lies more on societal values, for example, France (Grinbaum et al. 2018), Norway (Egeland et al. 2018) and Germany (Hahn et al. 2018). In some countries, the preferred method of creating societal value aligns with the 'science for society' model, for example, in Brazil (Reyes-Galindo and Monteiro 2018) and India (Srinivas et al. 2018), while in others public participation plays a strong role, for example, in the Netherlands and Germany. 
The reports also show that countries struggle to align their STI imaginaries with the local institutional realities of scientists, especially regarding the core criteria by which research organisations evaluate their researchers. As Part I shows, national policies can be very effective drivers for RRI adoption in organisations. However, many national reports highlight policies or framings that stress the importance for scientists to create societal value, but that leave their operationalisation to individual scientists. This can lead to confusion among scientists regarding what is expected of them, or to the implementation of policies in a superficial way that has little effect on existing practices: see for example the reports of Bulgaria (Damianova et al. 2018), China, Germany, India and Norway; see also Åm (2019). Making societal value creation the responsibility of research institutions also carries a risk, as it may disconnect this responsibility from the daily practices of researchers (see the Italy report). And a clear policy that offers prescriptions for operationalisation can lead to a lack of creativity and reflection on these operationalisations (see the France report), or to the perception that these responsibilities are a bureaucratic box-checking exercise rather than a vital part of research, as has been especially noted regarding ethics in research, in the comparative study of the ethics key in the RRI-Practice project (Hennen and Ladikas 2018).

The reports also show consistent concerns of scientists regarding these policies, particularly how they might affect their autonomy as researchers, and their ability to engage in fundamental research. These concerns may be brought up for different reasons, depending on the specific context of the country. For example, autonomy in Brazil is considered especially important to distance research institutions from 'undemocratic' influences, and fundamental research may be seen as an aim in itself, but also as contributing more societal value in the long run than applied research (see the Australia report). Another concern for scientists, that has received little attention in research, is whether research policies aimed at societal value creation, the implementation of which would require structural changes to institutions and research practice, are integrated parts of long-term, stable imaginaries, or rather fashions that will pass with the next election (Kaltenbrunner 2020). This holds particularly for countries where political regimes tend to change quickly (for example, Brazil and Bulgaria) or that are otherwise perceived to focus on short-term goals over long-term strategy (for example, Australia). Stability in research policy is crucial for structural implementation and this holds also for the RRI agenda.

\subsection{Administrative Style}

RRI tends to invoke consensus as the aim of (participative) decision processes on innovation. Ideally, all involved stakeholders come to agree on a given direction for an innovation (even if that means abandoning that innovation, as was the case for the SPICE project in Stilgoe et al. 2013). However, consensus may be difficult to obtain in practice (Blok 2014; Van Oudheusden 2014), and contention, conflict and 
struggle can have their own advantages, such as sharpening arguments and encouraging the participation of more diverse viewpoints (Swierstra and Rip 2007; Blok 2019). These different styles of interaction have been analysed in the sociotechnical imaginaries under the heading of 'administrative style'. As a general observation, the administrative styles of the participating countries differ widely. Some are quite consensus-oriented, such as Germany, the Netherlands and Norway. Others have a more contentious style: especially if consensus-oriented participation opportunities are limited (the US), or there is high distrust in politicians and experts (Brazil and France, and in certain areas Italy). Some reports do not mention a particularly contentious or consensus-oriented style, sometimes because there is a one-party system, or because there is little interaction of experts with the public to begin with (China, India).

The national case study reports show that having an open, deliberative, consensusoriented administrative style (e.g. Germany, the Netherlands, Norway) tends to align best with RRI ideals. For example, the Dutch National Research Agenda is a good example of including stakeholders and societal actors in science policy-making, that fits in the Dutch tradition of collaboration and deliberation (Netherlands report, pp. 20-21). Getting people to speak frankly about their hopes and concerns facilitates the discussion of values and possible futures; the interaction of people with different interests and viewpoints, particularly if more critical parties are involved, facilitates reflexivity.

While in theory a country could combine a contentious administrative style with more open and deliberative procedures, in our case studies there was a correlation between countries having a contentious administrative style and expert-driven decision-making (and, conversely, between countries having a consensus-oriented administrative style and more participatory modes of decision-making). This is hardly surprising: if a county relies on expert-driven decision-making, it has no need for deliberative fora. Moreover, many countries with a contentious administrative style had a de facto two-party system (Australia, Brazil, the UK, the US), where RRIrelevant topics such as gender, inclusion and social justice have become politicised and associated with one of the main parties. In those countries, there is the risk of RRI becoming increasingly aligned with the STI imaginary of one political party, rather than with a national imaginary that transcends party politics. Nevertheless, various reports (Brazil, France, Italy, the US) show that a (perceived) lack of proper participation channels, whether through expert or party dominance of STI governance, can give rise to public contestation and activism.

\subsection{Public Participation}

RRI assumes that research processes should be participatory, involving societal actors throughout the research process alongside STI (policy) experts. This is in contrast with earlier science governance models such as the 'linear model' and the 'science for society' model, as explained in the 'methodology' section. While no country 
in our study clearly adheres to the 'linear model', as witnessed by the sections on 'public participation' in the national sociotechnical imaginaries, the 'science for society' model is particularly visible in Brazil, India and the US. The 'deficit model' of science communication similarly assumes that participation is redundant: either the public doesn't understand the scientists, in which case it needs to be informed, or it does understand them, in which case it will immediately see the value of their work. This model is visible in STI governance in at least Australia, China, France, India, Italy, Norway (until 2008) and the UK (until the 00's).

That those models tend not to be sufficient to convince society at large of the value of STI, is shown by the fact that (perceived) distrust in science, and concerns about this among scientists and policy-makers, is widespread and has been noted in at least the reports of Australia, Bulgaria, China, France, Italy and the US. In several cases this distrust is fuelled by scientists having been involved in the development and implementation of socially controversial technologies, such as GMOs (China), nuclear technologies (France) or vaccines (Italy). This distrust can be a driver for a national STI imaginary to become more aligned with RRI: the reports of Germany and the UK show how policy measures have been taken in the past to increase public participation, as an explicit means of addressing this distrust.

More worrying cases of distrust in science are presented by the US and Brazil reports (and particularly in Monteiro 2020), where this distrust is actively promoted by dominant political parties to further their political agendas. While in both cases this has led to an awareness of the urgency of the issue by involved scientists, this policy pressure has also created very unfavourable conditions for a proper transition towards a more inclusive and reflexive relationship between science and society.

Concerning the participation of private actors in the STI system, while the RRIPractice project has not investigated private sector STI activities, it has noted that participation of non-academic actors in STI activities often involves public-private collaborations or triple-helix collaborations (for example, Italy and the UK). In no participating country is extensive public participation a structural part of the STI system, though the practice is relatively widespread in the Netherlands. However, experiments and examples of good practices can be found almost anywhere. As an aside, an STI system with little participation is not necessarily problematic for the RRI keys. As some reports illustrate (for example, Brazil), top-down policy-making by experts can quickly and effectively advance RRI keys in organisations, if those experts endorse them. However, in our case studies, the RRI imaginary aligns less well with those STI imaginaries in countries with more expert-driven decision-making, than with those in countries with more participatory decision-making procedures. 


\section{References}

Åm, H. 2019. Limits of decentered governance in science-society policies. Journal of Responsible Innovation 6 (2): 163-178.

Blok, V. 2014. Look who's talking: Responsible innovation, the paradox of dialogue and the voice of the other in communication and negotiation processes. Journal of Responsible Innovation 1 (2): 171-190.

Blok, V. 2019. From participation to interruption: Toward an ethics of stakeholder engagement, participation and partnership in CSR and responsible innovation. In Handbook on responsible innovation, ed. R. von Schomberg and J. Hankins, 243-258. Cheltenham: Edward Elgar.

Damianova, Z., M. Hajdinjak, E. Evgeniev, K. Ivanov, and O. Shentov. 2018. RRI-Practice report from national case study: Bulgaria, D.8.1. https://www.rri-practice.eu/knowledge-repository/pub lications-and-deliverables/.

Doezema, T., and D. Guston. 2018. RRI-Practice report from national case study: United States, D.12.1. https://www.rri-practice.eu/knowledge-repository/publications-and-deliverables/.

Egeland, C., T. Maximova-Mentzoni, A.B. Hanssen, and E.-M. Forsberg. 2018. RRI-Practice report from national case study: Norway, D.3.1. https://www.rri-practice.eu/knowledge-repository/pub lications-and-deliverables/.

Grinbaum, A., É. Klein, and M. Vandermersch. 2018. RRI-Practice report from national case study: France, D.6.1. https://www.rri-practice.eu/knowledge-repository/publications-and-deliverables/.

Hahn, J., L. Hennen, P. Kulakov, M. Ladikas, and C. Scherz. 2018. RRI-Practice report from national case study: Germany, D.4.1. https://www.rri-practice.eu/knowledge-repository/publications-anddeliverables/.

Hennen, L., and M. Ladikas. 2018. European Concepts and Practices of Technology Assessment. In Constructing a Global Technology Assessment: Insights from Australia, China, Europe, Germany, India and Russia, ed. J. Hahn, 47-77. Karlsruhe: KIT Scientific Publishing.

Kaltenbrunner, W. 2020. Managing budgetary uncertainty, interpreting policy. How researchers integrate "grand challenges" funding programs into their research agendas. Journal of Responsible Innovation.

Mejlgaard, N., C. Bloch, and E. Bergmann Madsen. 2018. Responsible research and innovation in Europe: A cross-country comparative analysis. Science and Public Policy 46 (2): 198-209. https://doi.org/10.1093/scipol/scy048.

Monteiro, M. 2020. Science is a war zone: Some comments on Brazil. Tapuya: Latin American Science, Technology and Society 3 (1): 4-8.

Neresini, F., and S. Arnaldi. 2018. RRI-Practice report from national case study: Italy, D.7.1. https:// www.rri-practice.eu/knowledge-repository/publications-and-deliverables/.

van Oudheusden, M. 2014. Where are the politics in responsible innovation? European governance, technology assessments, and beyond. Journal of Responsible Innovation 1 (1): 67-86.

Pansera, M., and R. Owen. 2018. RRI-Practice report from national case study: United Kingdom, D.5.1. https://www.rri-practice.eu/knowledge-repository/publications-and-deliverables/.

Reyes-Galindo, L., and M. Monteiro. 2018. RRI-Practice report from national case study: Brazil, D.13.1. https://www.rri-practice.eu/knowledge-repository/publications-and-deliverables/.

Sehic, S., and P. Ashworth. 2018. RRI-Practice report from national case study: Australia, D.14.1. https://www.rri-practice.eu/knowledge-repository/publications-and-deliverables/.

Srinivas, K.R., A. Kumar, and N. Pandey. 2018. RRI-Practice report from national case study: India, D.11.1. https://www.rri-practice.eu/knowledge-repository/publications-and-deliverables/

Stilgoe, J., R. Owen, and P. Macnaghten. 2013. Developing a framework for responsible innovation. Research Policy 42 (9): 1568-1580.

Swierstra, T., and A. Rip. 2007. Nano-ethics as NEST-ethics: Patterns of moral argumentation about new and emerging science and technology. Nanoethics 1 (1): 3-20.

van der Molen, F., L. Consoli, D. Ludwig, A. Pols, and P. Macnaghten. 2018. RRI-Practice report from national case study: The Netherlands, D.9.1. https://www.rri-practice.eu/knowledge-reposi tory/publications-and-deliverables/. 
World Economic Forum. 2018. The global competitiveness report 2018. Cologny/Geneva: World Economic Forum.

Zhao, Y., W. Zhang, M. Liao, L. Huang, F. Teng, R. Song, et al. 2018. RRI-Practice report from national case study: China, D.10.1. https://www.rri-practice.eu/knowledge-repository/publicati ons-and-deliverables/.

Open Access This chapter is licensed under the terms of the Creative Commons Attribution 4.0 International License (http://creativecommons.org/licenses/by/4.0/), which permits use, sharing, adaptation, distribution and reproduction in any medium or format, as long as you give appropriate credit to the original author(s) and the source, provide a link to the Creative Commons license and indicate if changes were made.

The images or other third party material in this chapter are included in the chapter's Creative Commons license, unless indicated otherwise in a credit line to the material. If material is not included in the chapter's Creative Commons license and your intended use is not permitted by statutory regulation or exceeds the permitted use, you will need to obtain permission directly from the copyright holder. 